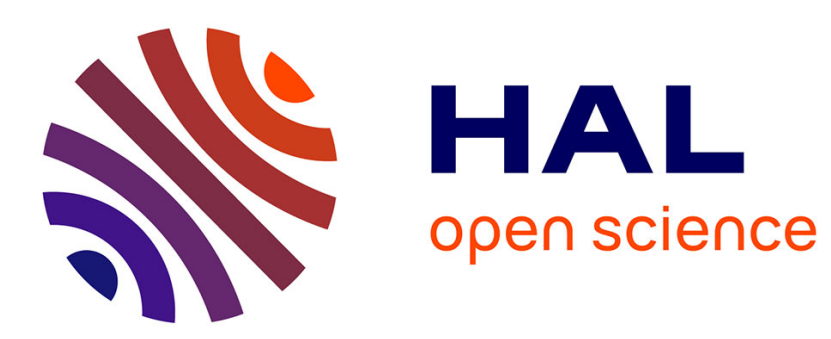

\title{
Optimizing the Power Take Off of a Wave Energy Converter with Regard to Wave Climate
}

\author{
Gaëlle Duclos, A. Babarit, A.H. Clement
}

\section{To cite this version:}

Gaëlle Duclos, A. Babarit, A.H. Clement. Optimizing the Power Take Off of a Wave Energy Converter with Regard to Wave Climate. Journal of Offshore Mechanics and Arctic Engineering, 2006, 128 (1), pp.56-64. 10.1115/1.2163877 . hal-00699464

\section{HAL Id: hal-00699464 \\ https://hal.science/hal-00699464}

Submitted on 7 May 2019

HAL is a multi-disciplinary open access archive for the deposit and dissemination of scientific research documents, whether they are published or not. The documents may come from teaching and research institutions in France or abroad, or from public or private research centers.
L'archive ouverte pluridisciplinaire HAL, est destinée au dépôt et à la diffusion de documents scientifiques de niveau recherche, publiés ou non, émanant des établissements d'enseignement et de recherche français ou étrangers, des laboratoires publics ou privés. 


\title{
Optimizing the Power Take Off of a Wave Energy Converter With Regard to the Wave Climate
}

\author{
Gaëlle Duclos, Aurélien Babarit, Alain H. Clément \\ Laboratoire de Mécanique des Fluides (CNRS-UMR6598) \\ Ecole Centrale de Nantes \\ 1, Rue de la Noë, 44300 Nantes, France
}

Considered as a source of renewable energy, wave is a resource featuring high variability at all time scales. Furthermore wave climate also changes significantly from place to place. Wave energy converters are very often tuned to suit the more frequent significant wave period at the project site. In this paper we show that optimizing the device neces-sitates accounting for all possible wave conditions weighted by their annual occurrence frequency, as generally given by the classical wave climate scatter diagrams. A generic and very simple wave energy converter is considered here. It is shown how the optimal parameters can be different considering whether all wave conditions are accounted for or not, whether the device is controlled or not, whether the productive motion is limited or not. We also show how they depend on the area where the device is to be deployed, by applying the same method to three sites with very different wave climate.

\section{A Generic Wave Energy Device: Working Principle and Governing Equations}

In this study, we shall use as an example a very simple point absorber device with a single degree of freedom. Namely, we will consider a submerged vertical cylinder constrained to move in heave motion only, under the action of wave excitation forces. The stroke of the vertical motion apart from the equilibrium position, denoted by $\zeta(t)$, is limited between $-b$ and $+b$ with $b$ $=5 \mathrm{~m}$ to account for endstops (Fig. 1).

The body oscillates vertically under the action of excitation forces, radiation forces, restoring forces idealized here as a single spring of stiffness $k$, and a damping force proportional to the velocity (with damping coefficient $B$ ) supposed to model the action of the Power Take Off (PTO) mechanism. This generic system belongs to the same family as some real projects currently being tested in full scale.

A linear approach will be adopted here for modeling hydrodynamics, in such a way that the behavior of the body in waves will be governed by the following integro-differential equation:

$$
\left(M+\mu_{\infty}\right) \ddot{\zeta}+\int_{0}^{t} \dot{\zeta} K(t-\tau) d \tau+B \dot{\zeta}+k \zeta=F_{\text {ex }}(t)
$$

where one can recognize the Cummins' decomposition [1] of the radiation forces into an instantaneous added mass term $\mu_{\infty} \ddot{\zeta}$ and a memory term expressed by a convolution product $\int_{0}^{t} \dot{\zeta}(\tau) K(t$ $-\tau) d \tau$. The kernel $K$ of this integral, generally named impulse response function, or sometimes retardation function, depends essentially on the shape of the body. It can be computed directly in the time domain by using dedicated seakeeping BEM codes like ACHIL3D [2], TIMIT,.... But it can also be deduced through a Fourier transform of the frequency domain hydrodynamic coefficients (added mass and damping coefficient) for which dedicated computer codes like WAMIT [3], DIODORE, AQUADYN [4],.., can be used. In the present time-domain linear formulation, the free motion $\zeta(t)$ of the device may be calculated by integrating (1) for a given history of the wave excitation forcing term $F_{\mathrm{ex}}(t)$, and given initial conditions $\zeta(0)$ and $\dot{\zeta}(0)$. Once the impulse response function $K(t)$ has been determined, it can be further approximated by a sum of exponential functions by using Prony's method as described in [5]. This allows replacing the integro-differential form (1) by a system of ordinary differential equations (ODE) like (2), generally better suited to the numerical simulation,

$$
\left\{\begin{array}{c}
\left(M+\mu_{\infty}\right) \ddot{\zeta}(t)+\sum_{i=0}^{N} I_{i}(t)+B \dot{\zeta}(t)+k \zeta(t)=F_{\mathrm{ex}}(t) \\
\dot{I}_{i}(t)=\beta_{i} I_{i}(t)+\alpha_{i} \dot{\zeta}(t)
\end{array}\right.
$$

The device as described up to now is a linear mechanical oscillator. The mean power $\hat{P}$ extracted by the PTO over a time range $T$ is given by

$$
\hat{P}=\frac{B}{T} \int_{0}^{T} \dot{\zeta}^{2}(\tau) d \tau
$$

The power of the incident wave train $\hat{P}_{i}$ is classically expressed in $\mathrm{kW}$ per meter of the wave front (generally considering incident waves as a $2 \mathrm{D}$ train of long crested irregular waves). Then if we reduce $\hat{P}$ (Eq. (3)) the power extracted by the device, by the power of incident waves to quantify the efficiency of the system, the result will be expressed in meters of the wave crest; it is the so-called capture width of the device. Further dividing this capture width by the width of the device itself, we obtain a nondimensional number which is called capture width ratio (sometimes shortened into capture ratio). This ratio will be used here to quantify the energetic efficiency of the device.

This device is basically a linear mechanical oscillator, with a natural circular frequency $\omega_{0}$ depending on the spring coefficient $k$, on the proper mass and the added mass of the body. When it is left uncontrolled, the designer must choose the natural frequency to make the device the most possible efficient for the site where it will be deployed.

One condition for maximizing converted energy in harmonic regime is the phase condition imposing the oscillating velocity of the body to be in phase with the excitation force on the body (phase control). This happens exactly when the wave frequency equals the natural frequency of the body. In order to maximize the extracted power, an optimum amplitude condition must also be satisfied. Basically, if the amplitude of the motion is uncon- 


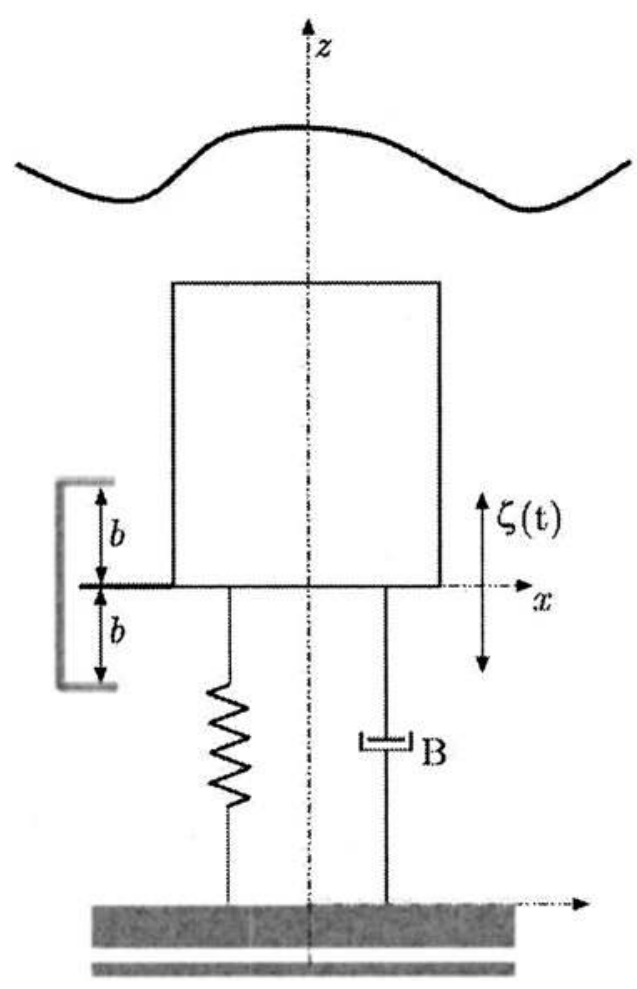

Fig. 1 The generic device: working principle

strained, this condition states that the resistive load $B$ of the PTO should equal the hydrodynamic damping coefficient at the incident wave frequency. It is therefore easy to understand that in random sea, an uncontrolled device can't be optimally efficient at any time.

A device is said to be controlled if it can adapt itself to the incident wavetrain, wave after wave. The control can be either continuous or discrete (see Falnes [6] for a recent review about this topic).

Continuous control is achieved by acting on the mechanical parameters of the PTO in order to respect the two above conditions. A lot of work has been done about this topic; see, e.g., $[7,5,8]$.

In the present study, we have used instead another approach to Wave Energy Converters (WECs) control, called latching control. Unlike the previously continuous one, this method is discrete. It consists of locking (latching) the motion of the body at the moment when its velocity vanishes, and waiting for the wave force having reached the most favorable phase to release the body. The body then starts moving from this initial position to the next velocity vanishing position where it is latched again, and so on. Instead of being a smooth, continuous function of time, the position of the body is a succession of ramps of transient motions separated by stages of rest. The action control upon the system is therefore binary: either the body is latched, either it is free to move, which explains the meaning of the term "discrete" used in this context. The instant of latching is imposed by the dynamics of the body (i.e., vanishing velocity); thus, the control variable here is the duration of the latching phase, or equivalently the instant of release. A lot of work has been done by U.A. Korde about it with WEC where energy absorption and latching are achieved by means of pneumatic cylinders with open/close valves; see $[9,10]$. Here, latching is applied externally on the heave motion of the buoy, as proposed by Budal and Falnes [11] and investigated by Greenhow and White [12] and by Babarit, Duclos, and Clement [13].

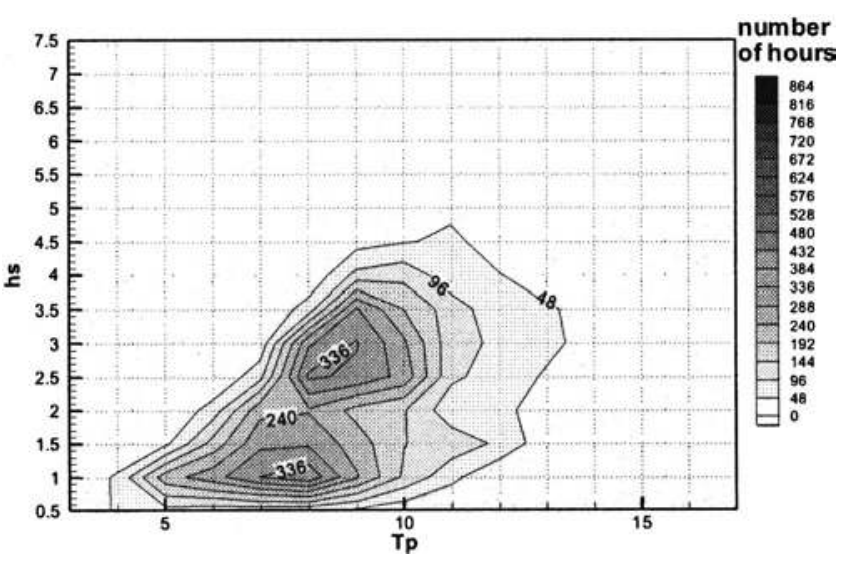

Fig. 2 Sea state occurrence frequency for the Yeu Island

\section{Three Project Sites}

Optimization of such a device consists of determining $B$ and $k$ (or equivalently the natural period $T_{0}$ since $k$ is proportional to $\left.1 / T_{0}\right)$ to obtain as large a yearly energy output as possible. For each wave condition (couple $H_{s}, T_{s}$ ) five different wave excitation time series (for five different set of random phases) of $1 \mathrm{~h}$ have been simulated. If for one of the five wave time series, $|\zeta(t)|$ reach a value bigger than $b$ at least once, the device is turned into the survival condition and the energy produced is set equal to zero for this wave condition.

This optimization work was performed for three different sites: Yeu Island which is located in front of the french Atlantic coast near Nantes. The scatter diagram for this place giving the probability of occurrence of each sea state, see Fig. 2, was found on www.cetmef.equipement.gouv.fr, it has been established from field data collected by a wave measuring buoy.

The two others are located around the Reunion Island in the Indian Ocean: Saint Pierre is on the south coast of the island and P67 is a reference meteorological point located in open sea at latitude $21 \mathrm{deg}$ and longitude $55.5 \mathrm{deg}$. Wave scatter diagrams for this two sites have been found in a report by Perrono [14]. The first one, Fig. 3, was obtained through some in situ measurements whereas the second one, Fig. 4, is the result of a wind-wave numerical model.

The first two sites have the same level of mean annual wave power per unit width but their scatter-diagrams (frequency occurrence for each couple $H_{s}, T_{s}$ ) are different. The wave power of the third site is lower. Figure 2 shows that the Yeu Island features two distinct prevailing sea states: the first one, $H_{s}=1.0 \mathrm{~m}, T_{s}=8 \mathrm{~s}$, is faintly energetic $(\approx 3 \mathrm{~kW} / \mathrm{m}$, mean power per meter wave front

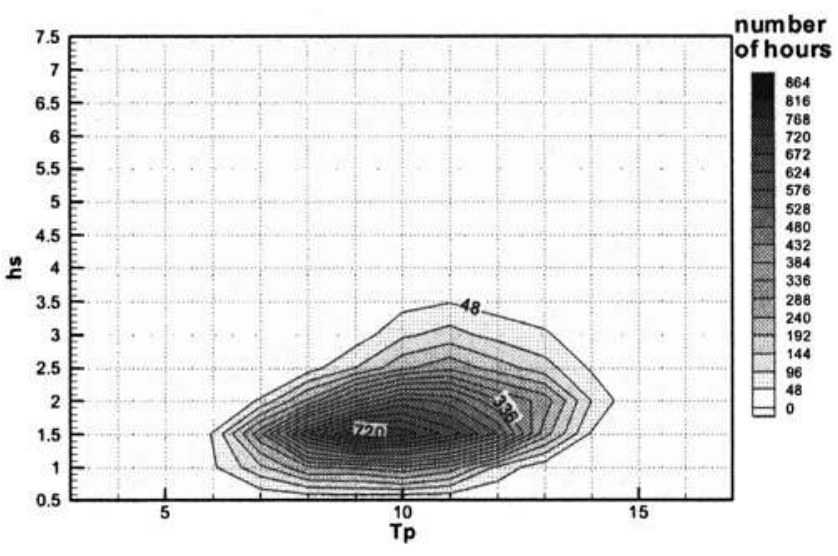

Fig. 3 Sea state occurrence frequency for point 67 


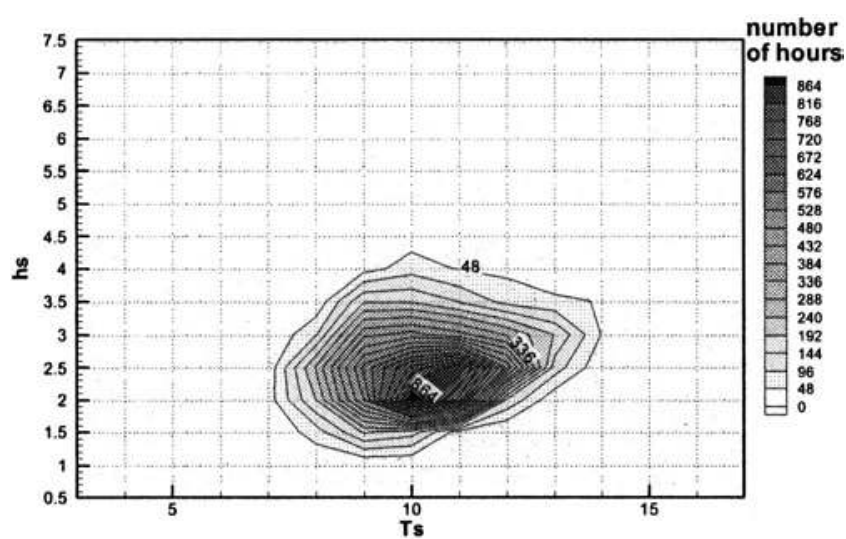

Fig. 4 Sea state occurrence frequency at St. Pierre

$\hat{P}_{i}=0.55 \times H_{s}^{2} \times T_{z}$ in $\mathrm{kW} / \mathrm{m}$ with $\left.T_{z}=T_{s} / 1.4\right)$, whereas the second one, $H_{s}=2.5 \mathrm{~m}, T_{s}=8 \mathrm{~s}$, is far more energetic $(\approx 20 \mathrm{~kW} / \mathrm{m})$. So we have considered two different dominant sea states for this place. At P67 and Saint Pierre sites, prevailing sea state powers are, respectively, about $16 \mathrm{~kW} / \mathrm{m}$ and $8 \mathrm{~kW} / \mathrm{m}$. Table 1 sums up these prevailing sea states and the related power for each of the three sites considered herein.

\section{Results}

Results for the mean annual production are generally plotted here in terms of capture width ratio which is the common measure of the point absorber device efficiency in wave energy literature. When results are given in terms of energy, they are computed as the mean of five different time series, or in terms of mean power which is the energy defined above divided by the length of the time series.

3.1 The Optimal Natural Period. Let us first consider the evolution of capture width versus excitation period for various natural periods of the system. Results are plotted in Fig. 5 for the uncontrolled device and in Fig. 6 for the controlled one. In this section, the significant wave amplitude is constant and small $(1 \mathrm{~m})$, and the PTO damping coefficient is set to its optimal value for regular wave $\left(B_{\text {optimal }}=\mathrm{Ca}\left(\omega_{0}\right)\right)$. In this first series of simulations the amplitude of the vertical motion was not limited and so $|\zeta(t)|$ can be greater than $b$.

Capture widths of controlled devices are about twice greater than uncontrolled ones, and system bandwidth are also larger. In the controlled case, and for each value of the natural period $T_{0}$, maximal capture width seems to occur for significant wave period $T_{s}$ a bit larger than $T_{0}$. When the device is left uncontrolled, the maximal capture width is reached when $T_{s}$ is very close to $T_{0}$. Figures 7 and 8 show that vertical motion amplitude increases with $T_{0}$ and confirm that amplitudes are larger when the device is controlled. Even for such a small wave amplitude $(1 \mathrm{~m})$, when the natural frequency of the system is set to $10 \mathrm{~s}$, the body response $|\zeta(t)|$ can overpass its limit value $b=5 \mathrm{~m}$.

Table 1 Prevailing sea states of the three sites

\begin{tabular}{ccccc}
\hline \hline & Yeu Island & Point 67 & St. Pierre \\
\hline Mean power $(\mathrm{kW} / \mathrm{m})$ & \multicolumn{2}{c}{25.9} & 29.6 & 15.4 \\
Prevailing $H s(\mathrm{~m})$ & 1.0 & 2.5 & 2.0 & 1.5 \\
Prevailing $T s(\mathrm{~s})$ & 8 & 8 & 10 & 9 \\
Power of prevailing sea state & 3 & 20 & 16 & 8 \\
Yearly number of hours & 370 & 345 & 914 & 755 \\
\hline \hline
\end{tabular}

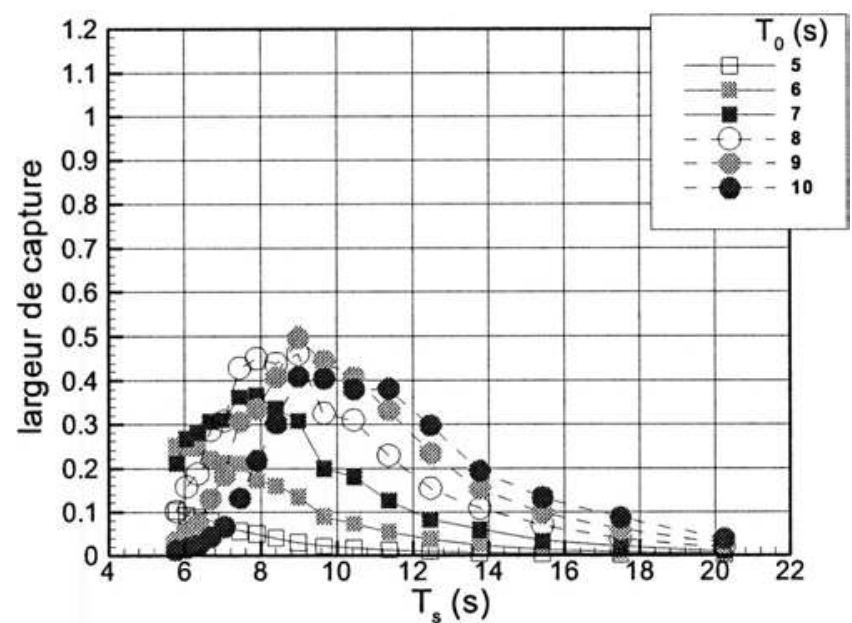

Fig. 5 Capture width ratio versus $T_{s}$, varying $T_{0}$, with $B$ $=\mathrm{Ca}\left(\omega_{0}\right)$ (uncontrolled device)

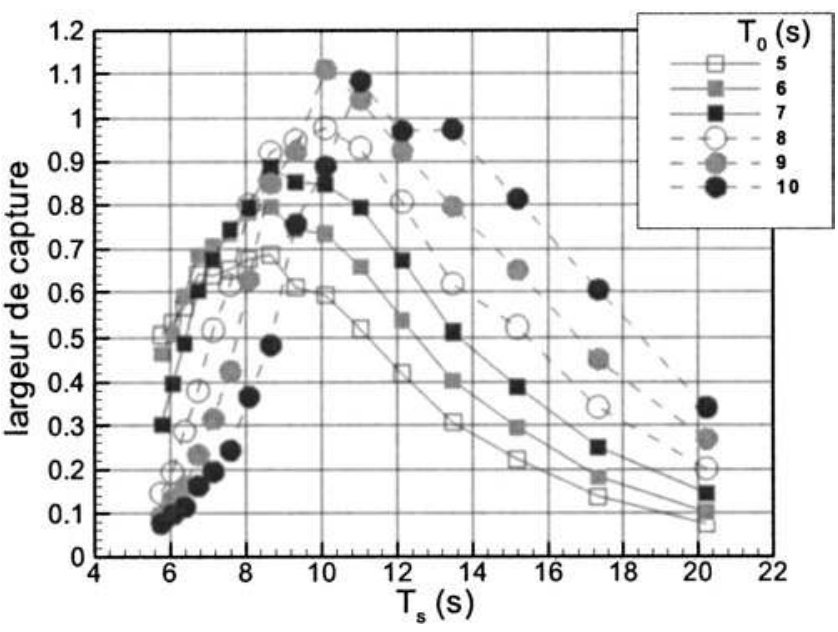

Fig. 6 Capture width ratio versus $T_{s}$, varying $T_{0}$, with $B$ $=\mathrm{Ca}\left(\omega_{0}\right)$ (controlled device)

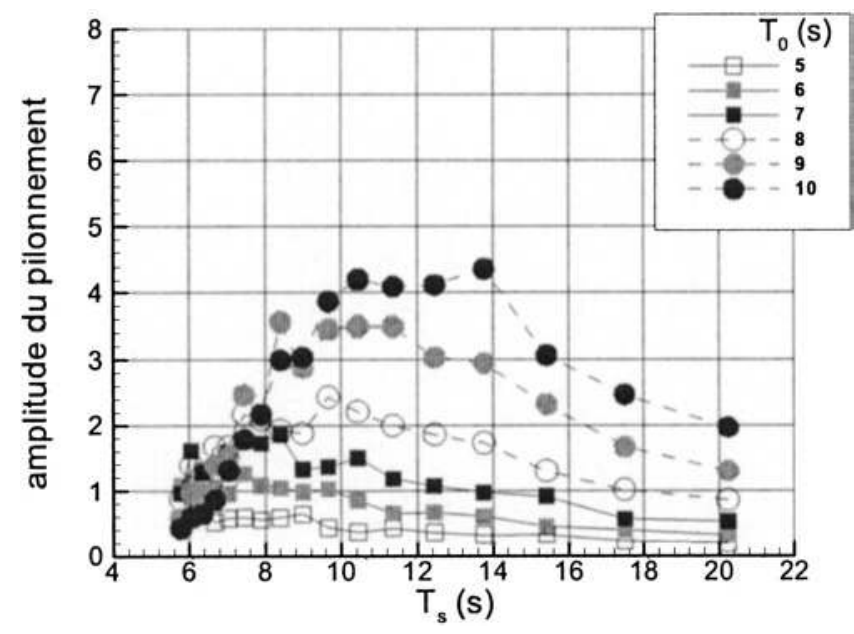

Fig. 7 Heave motion amplitude versus $T_{s}$, varying $T_{0}$, with $B$ $=\mathrm{Ca}\left(\omega_{0}\right)$ (uncontrolled device) 


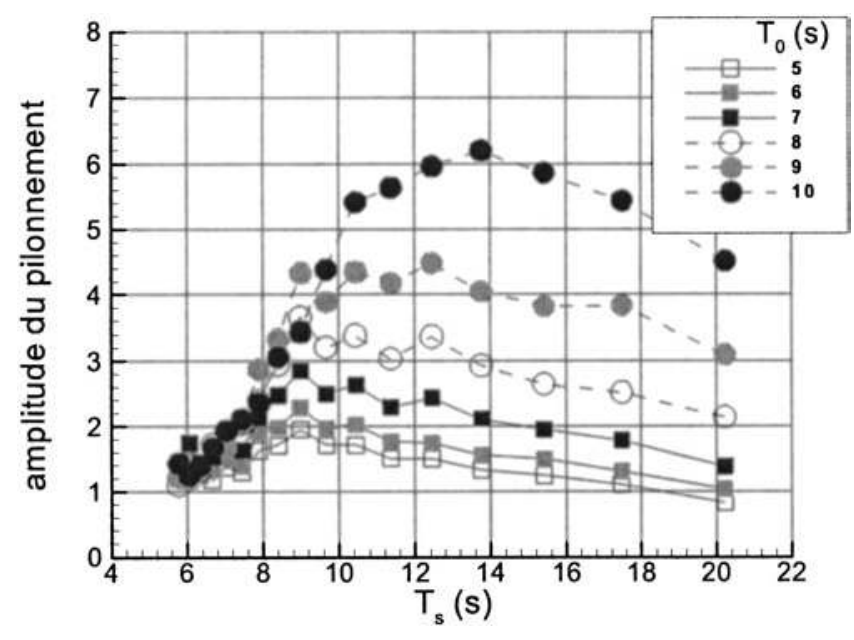

Fig. 8 Heave motion amplitude versus $T_{s}$, varying $T_{0}$, with $B$ $=\mathrm{Ca}\left(\omega_{0}\right)$ (controlled device)

3.2 The PTO Damping Coefficient. In this part, we will vary the PTO damping coefficient $B$ to assess its influence on the capture width. In this section the natural period of the system will be kept equal to $9 \mathrm{~s}$ and the significant wave height of the tested sea states set to $1 \mathrm{~m}$.

Again we can see here the benefit brought by the control on the capture width ratio, especially for the small values of $B$.

For a given sea state and a given $T_{0}$, the capture width (or $\hat{P}$ ) according to $B$ is a bell shaped curve. It is easy to understand that when $B=0$ (no PTO) and $B=\infty$ (PTO infinitely stiff), then no power will be output from the device $(\hat{P}=0)$; when $B$ is small $\zeta$ tends to be high and oppositely when $B$ is high $\zeta$ decreases. It is important to notice that the maximum that occurs for values of $B$ are very different, whether the device is controlled or not. When the device is uncontrolled, all $B$ give results very close to each others, and better results are obtained with $B=100,000$ (Fig. 9). When the device is controlled, results are very different according to $B$, and the best results are obtained with smaller values of $B$ in the range $(20,000-30,000)$, that is close to $\mathrm{Ca}\left(\omega_{0}\right)(\mathrm{Ca}(2 \pi / 9)$ $=28,000$ ). For $B$ between 200,000 and 300,000 results are similar whatever the devices are controlled or not.

This first study about damping coefficient does not permit us to conclude definitely on the optimal value of $B$ because we didn't consider in this section any bound for the vertical motion; neither

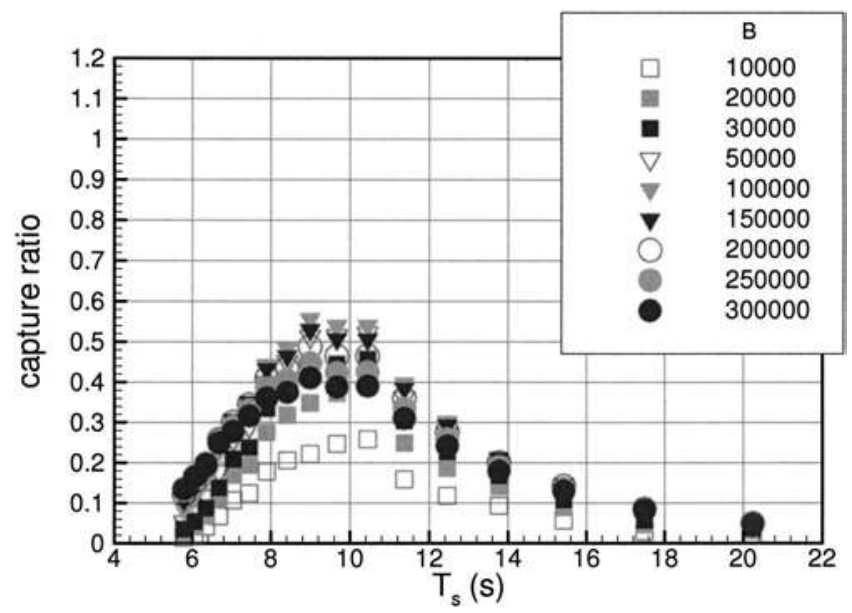

Fig. 9 Capture width ratio versus $T_{s}$, varying $B$, with $T_{0}=9 \mathrm{~s}$ (uncontrolled device)

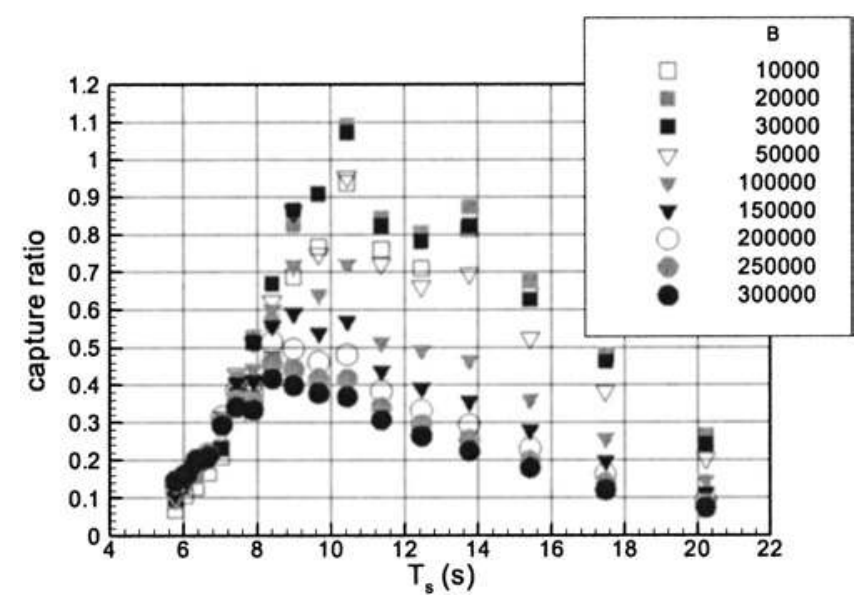

Fig. 10 Capture width ratio versus $T_{s}$, varying $B$, with $T_{0}=9 \mathrm{~s}$ (controlled device)

the fact that for small damping coefficients, the motion amplitudes can be very large, especially when the device is controlled (Fig. 10).

3.3 Optimization of the Device by Using the Prevailing Sea State. In this section, we are looking for the couple of mechanical parameters $\left(B, T_{0}\right)$ maximizing energy production over a full year $(8760 \mathrm{~h})$ working in the prevailing sea state of each site (let us be reminded that there are two distinct prevailing sea states for the Yeu Island site). Simulations were performed on both the controlled and uncontrolled devices at the three sites. Results are plotted in Figs. 11-18 and summarized in Table 2.

In Figs. 13-18 energy was set to zero for some couples $\left(B, T_{0}\right)$; the reason is that, for these sets of parameters, the vertical motion should overpass its imposed limits $\pm b$ and therefore the real device would normally be put in survival condition. The conclusions are similar for all the three locations:

(1) for the uncontrolled device $\left(T_{0}\right)_{\text {optimal }}=T s$, whereas $\left(T_{0}\right)_{\text {optimal }}<T s$ for the controlled one;

(2) $B_{\text {optimal }}$ is always smaller for the controlled device than for the uncontrolled device;

(3) energy produced with the optimal couple $\left(B, T_{0}\right)$ is always larger when the device is controlled.

We can observe that in some cases $B_{\text {optimal }}$ is the smallest $B$ (named $B_{\min }$ ) for which the device does not reach the endstops $b$ (see Figs. 13-16). Figures 11 and 12 which correspond to a low energetic prevailing sea state show $B_{\text {optimal }}$ bigger than $B_{\min }$. This

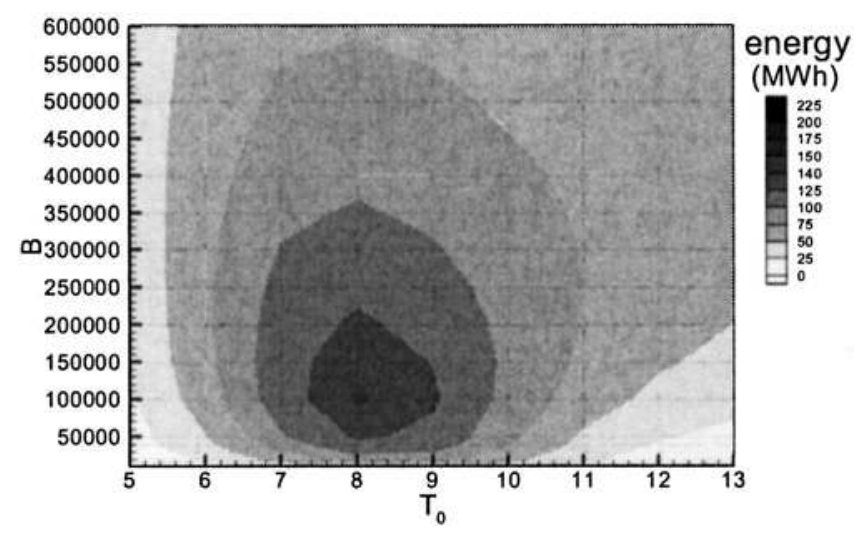

Fig. 11 Influence of $B$ and $T_{0}$ on annual energy production (uncontrolled device), $T_{s}=8 \mathrm{~s}, H_{s}=1 \mathrm{~m}$ 


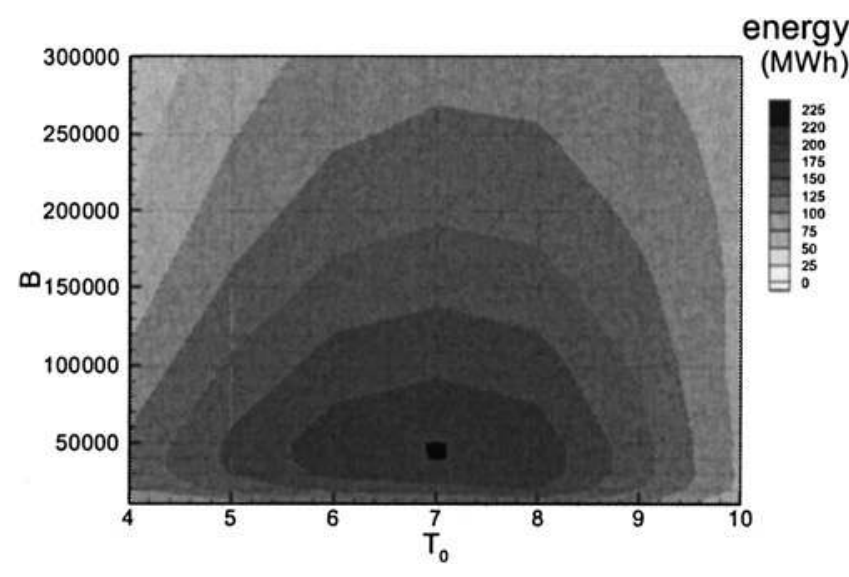

Fig. 12 Influence of $B$ and $T_{0}$ on annual energy production (controlled device), $T_{s}=8 \mathrm{~s}, H_{s}=1 \mathrm{~m}$

difference depends on the energy of the considered sea state, and the critical energy threshold seems to be lower when the device is controlled (see Figs. 17 and 18). This can be explained by a larger motion amplitude of this device in comparison with the uncontrolled device.

3.4 Optimization Based on the Whole Sea States Statistics. In this second approach we are seeking for the couple of mechanical parameters $\left(B, T_{0}\right)$ maximizing energy production over a full working year when one takes into account all the possible sea

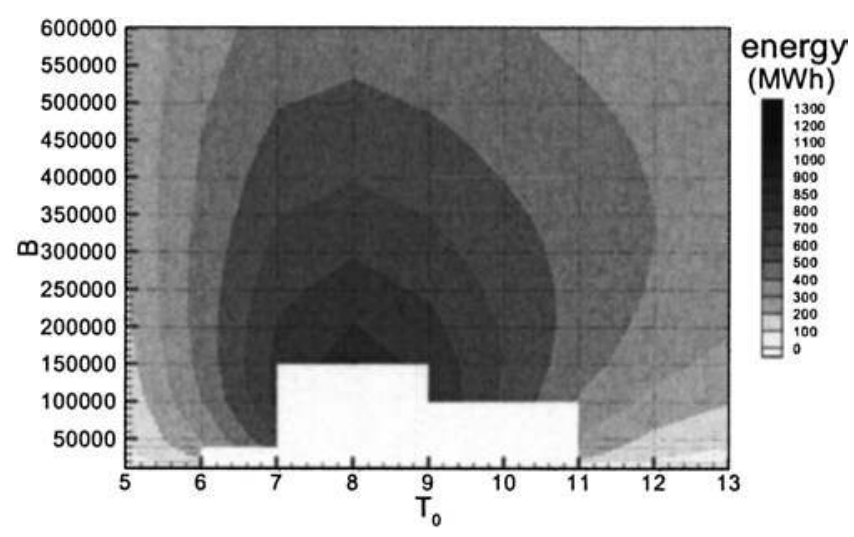

Fig. 13 Influence of $B$ and $T_{0}$ on annual energy production (uncontrolled device), $T_{s}=8 \mathrm{~s}, H_{s}=2.5 \mathrm{~m}$

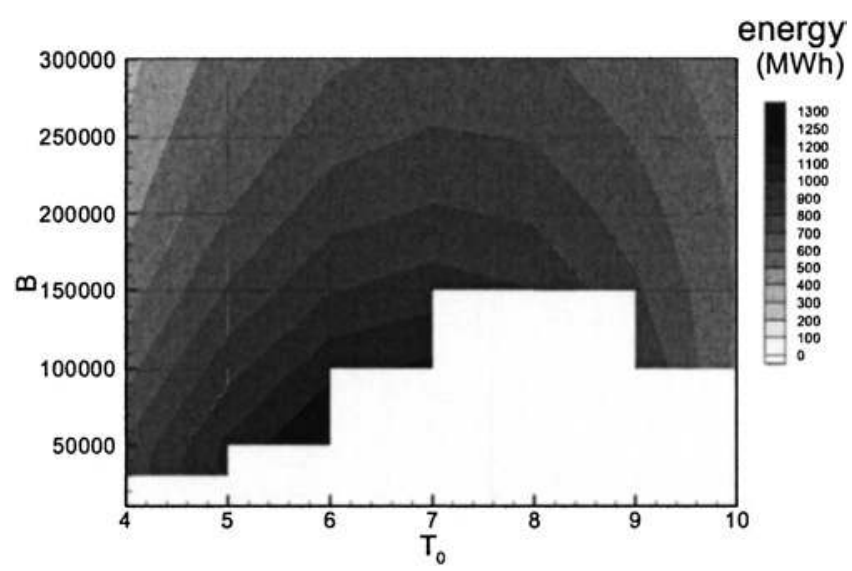

Fig. 14 Influence of $B$ and $T_{0}$ on annual energy production (controlled device), $T_{s}=8 \mathrm{~s}, H_{s}=2.5 \mathrm{~m}$

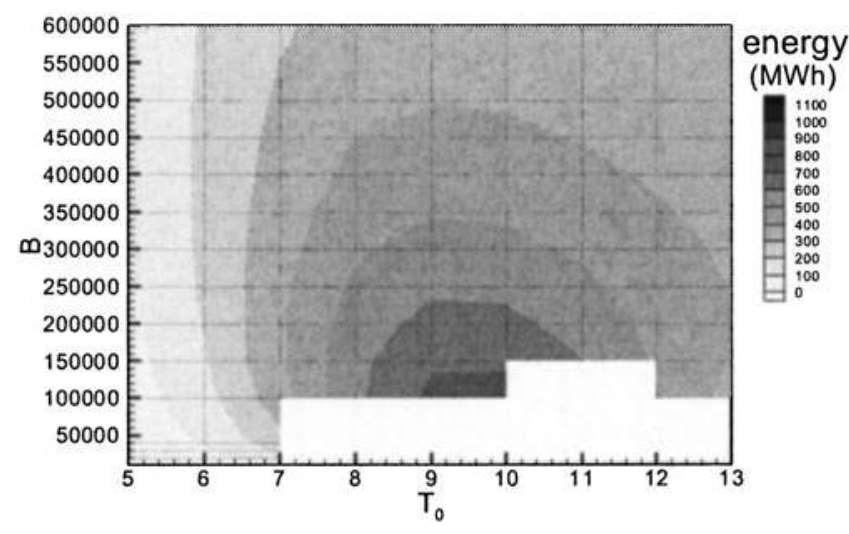

Fig. 15 Influence of $B$ and $T_{0}$ on annual energy production (uncontrolled device), $T_{s}=10 \mathrm{~s}, H_{s}=2 \mathrm{~m}$

states weighted by their probability of occurrence, as given by the scatter diagram of each site. Figures 19-24 show the results of these simulations, and the first conclusions are similar:

(1) $\left(T_{0}\right)_{\text {optimal }}$ are smaller for the controlled device than for the uncontrolled device;

(2) $B_{\text {optimal }}$ are smaller for the controlled device than for the uncontrolled device;

(3) the maximum capture width ratio is always better for the controlled device.

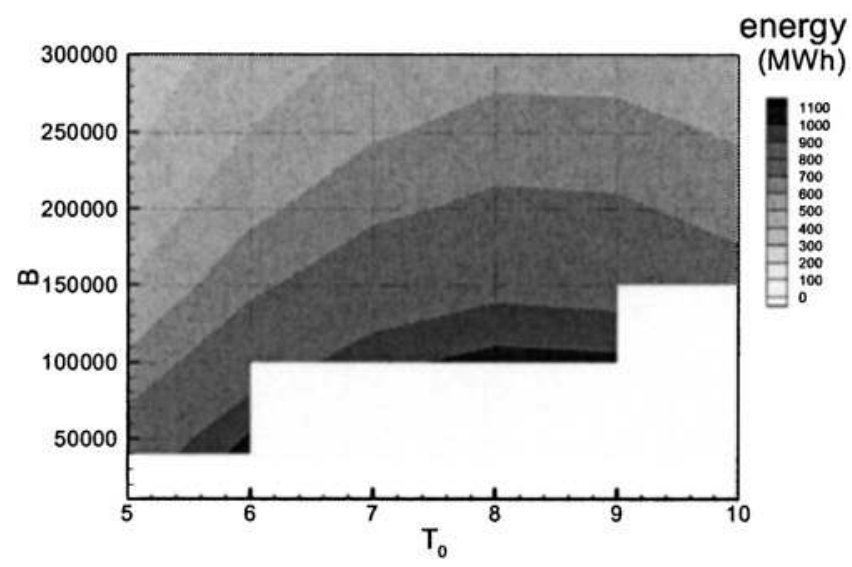

Fig. 16 Influence of $B$ and $T_{0}$ on annual energy production (controlled device), $T_{s}=10 \mathrm{~s}, H_{s}=2 \mathrm{~m}$

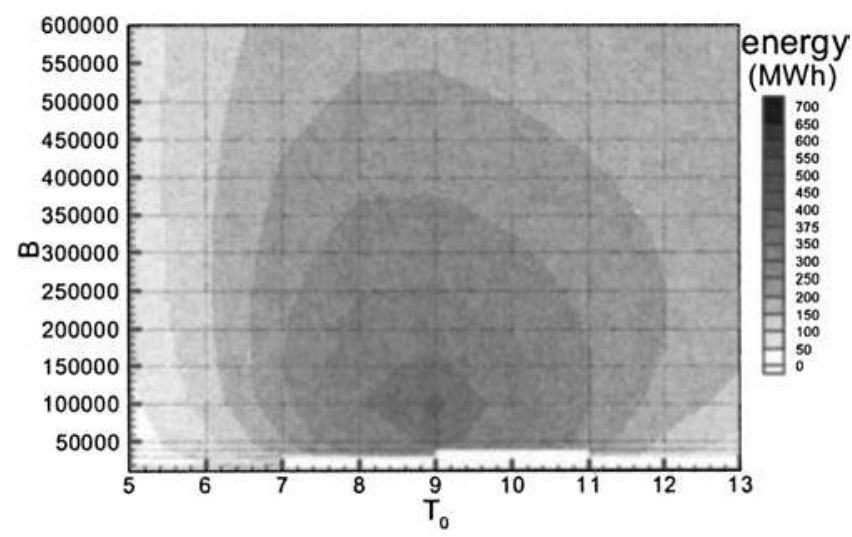

Fig. 17 Influence of $B$ and $T_{0}$ on annual energy production (uncontrolled device), $T_{s}=9 \mathrm{~s}, H_{s}=1.5 \mathrm{~m}$ 


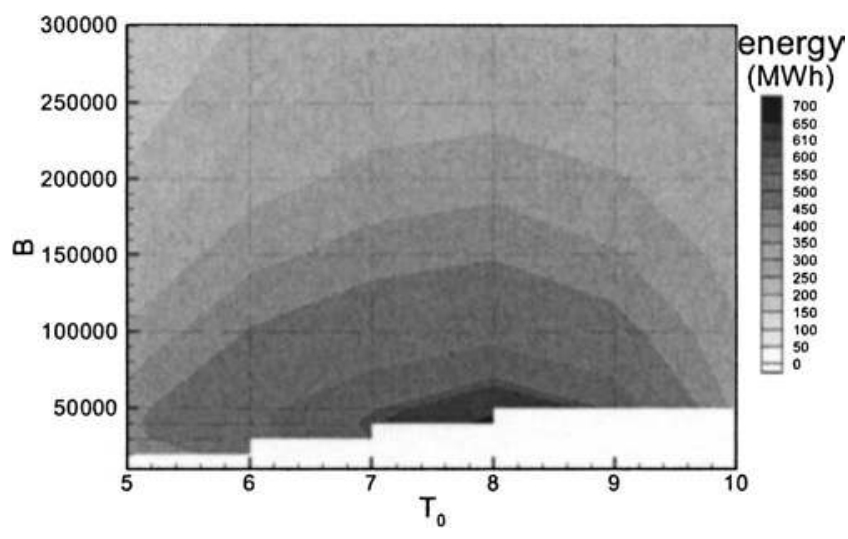

Fig. 18 Influence of $B$ and $T_{0}$ on annual energy production (controlled device), $T_{s}=9 \mathrm{~s}, H_{s}=1.5 \mathrm{~m}$
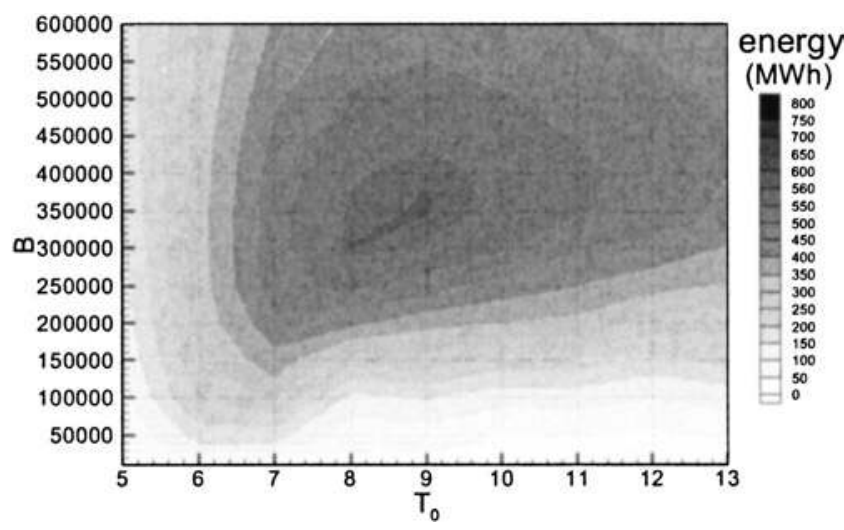

Fig. 19 Influence of $B$ and $T_{0}$ on annual energy production at Yeu Island (uncontrolled device)

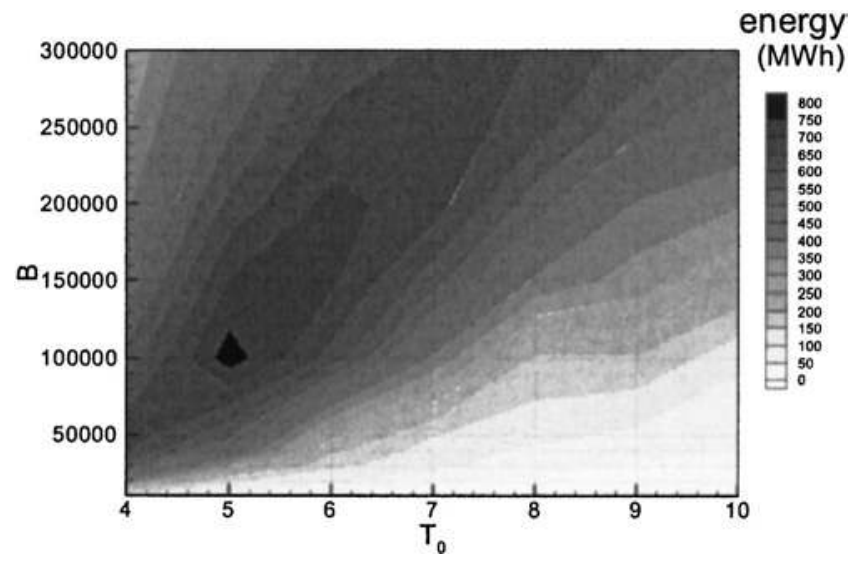

Fig. 20 Influence of $B$ and $T_{0}$ on annual energy production at Yeu Island (controlled device)

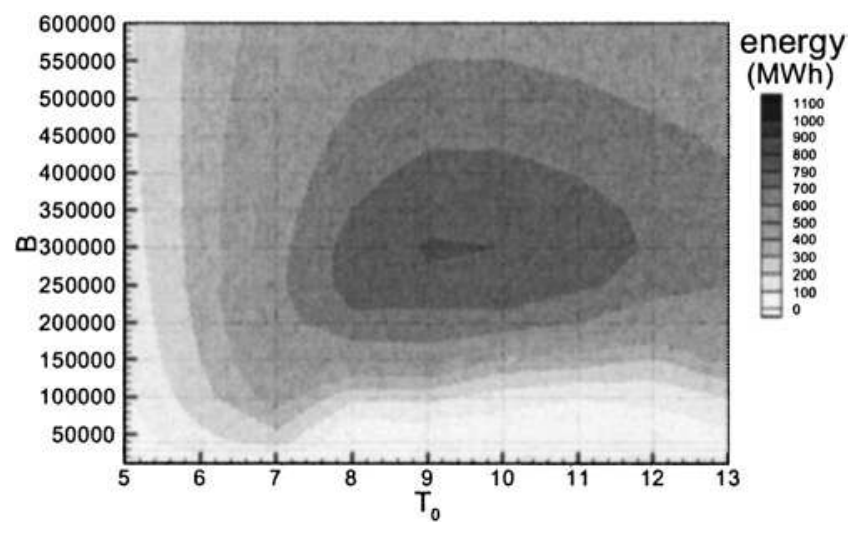

Fig. 21 Influence of $B$ and $T_{0}$ on annual energy production at P67 (uncontrolled device)

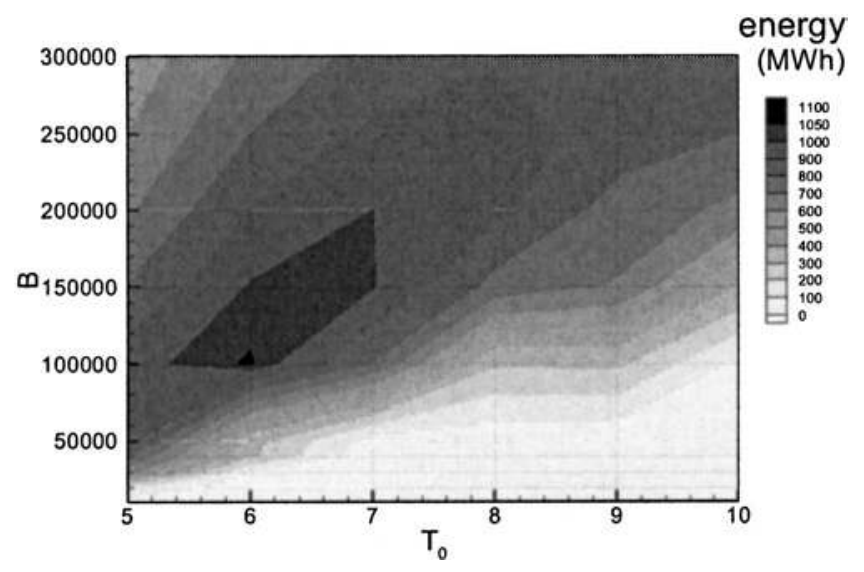

Fig. 22 Influence of $B$ and $T_{0}$ on annual energy production at P67 (controlled device)

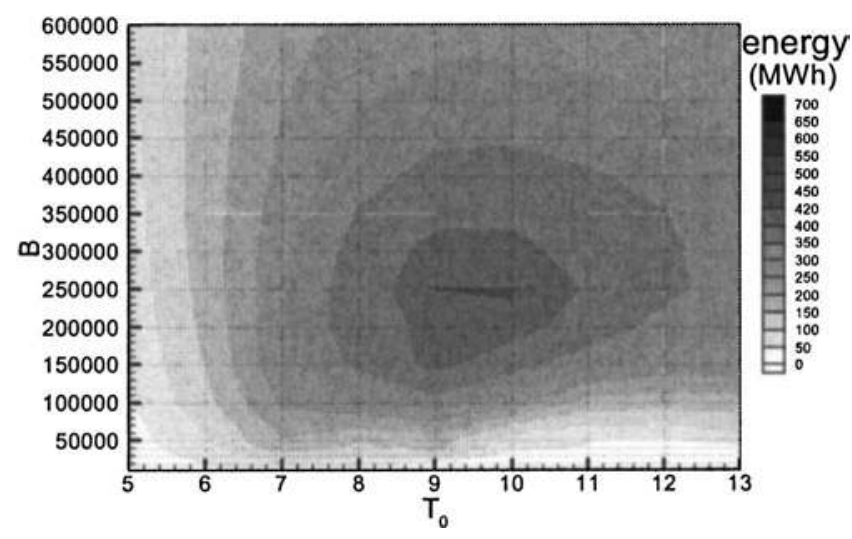

Fig. 23 Influence of $B$ and $T_{0}$ on annual energy production at St. Pierre (uncontrolled device)

Table 2 Result of the optimization of $(T 0, B)$ based on prevailing sea states

\begin{tabular}{|c|c|c|c|c|c|c|}
\hline & \multirow[b]{2}{*}{ Prevailing $H_{s}(\mathrm{~m})$} & \multirow[b]{2}{*}{ Prevailing $T_{s}(\mathrm{~s})$} & \multicolumn{2}{|c|}{ Uncontrolled } & \multicolumn{2}{|c|}{ Controlled } \\
\hline & & & $T_{0}(\mathrm{~s})$ & $B(\mathrm{~N} \mathrm{~s} / \mathrm{m})$ & $T_{0}(\mathrm{~s})$ & $B(\mathrm{~N} \mathrm{~s} / \mathrm{m})$ \\
\hline Yeu (1) & 1.0 & 8 & 8 & 100,000 & 7 & 50,000 \\
\hline Yeu (2) & 2.5 & 8 & 8 & 150,000 & 6 & 50,000 \\
\hline Point 67 & 2.0 & 10 & 10 & 100,000 & 6 & 40,000 \\
\hline St. Pierre & 1.5 & 9 & 9 & 100,000 & 8 & 40,000 \\
\hline
\end{tabular}




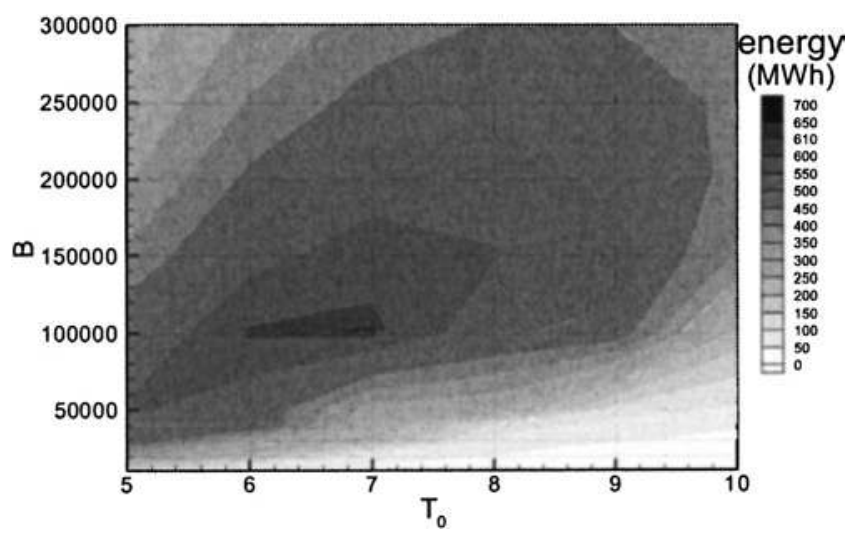

Fig. 24 Influence of $B$ and $T_{0}$ on annual energy production at St. Pierre (controlled device)

The optimal couples $\left(B, T_{0}\right)_{\text {optimal }}$ for each location and for the two optimization methods (by using only prevailing sea state or all sea states statistics) are summarized in Table 3 for the uncontrolled device and in Table 4 for the controlled device. We also report in the tables the energy produced over 1 year by the device working in all sea states (with their frequency occurrences) at each site, computed by using the couples $\left(B, T_{0}\right)_{\text {optimal }}$ obtained by both methods.

Both methods provide values of $\left(T_{0}\right)_{\text {optimal }}$ very close to the prevailing $T s$ if the device is uncontrolled, and smaller otherwise. Values of $B_{\text {optimal }}$ are very different and we can observe than those obtained by using all the sea states are always larger. This can be explained by the fact that the device must work in sea states where wave amplitude is larger than the prevailing amplitude, and for which it may be put in survival condition if the damping coefficient is too low.

Looking at energy production in Tables 3 and 4, we can see that devices tuned by using all sea state statistics for a given site allow us to produce more energy. As can be expected, the most efficient device is tuned that way, and controlled. The gain in energy output obtained by selecting the best optimization method can be as high as $400 \%$.

Let's compare results obtained for St. Pierre with those obtained for the P67 site: (a) For the first place and for the uncontrolled device, the optimization method allows a small gain, $25 \%$, versus $420 \%$ for the second place;

(b) If the device is tuned by using only the prevailing sea state, the control results in a loss of efficiency of about $50 \%$, but an increase of $100 \%$ for the other place.

To understand these differences, we can look at Figs. 25 and 26 which show the optimized device working in all four situations at these two sites. We have plotted, for each sea state, the mean annual extracted power: Fig. 25 is related to St. Pierre while Fig. 26 to the P67 place. For the uncontrolled devices the results are plotted in the top figures, whereas results for the controlled device are plotted in the bottom figures: the left plots $(a)$ and $(c)$ correspond to the devices tuned by using only the prevailing sea state, and the right plots $(b)$ and $(d)$ at the devices tuned with the detailed method.

The first difference (previously quoted) between this two places can be explained by the $B_{\text {optimal }}$ values. Indeed for P67 site $B_{\text {optimal }}$ is equal to $B_{\min }$ (see Fig. 15) and so it is easy to understand that in a sea state a bit more energetic than the prevailing sea state, the device is put in survival condition. Figure 26(a) proves that the device is stopped very often. In this case the cumulated working time is very short $(2354 \mathrm{~h})$. We can see in Fig. 26(b), that the detailed optimization method, by providing a bigger $B_{\text {optimal }}$, enables the device to work more frequently and in more energetic sea states. For the St. Pierre site, the $B_{\text {optimal }}$ is larger than $B_{\min }$ and the device will work in more energetic sea state than that used for the optimization. Figure 25(a) confirms this and in this case the device works over a long period of time $(7350 \mathrm{~h})$. So even if the other method of optimization gives a bigger value of $B_{\text {optimal }}$, the working time can be only a bit longer and so the production of energy can only be a bit higher.

Let's now turn to the second difference mentioned above: for the P67 site, whether the device is controlled or not, $B_{\text {optimal }}$ is in both case equal to $B_{\min }$. We can see by comparing Figs. $26(a)$ and $26(c)$ that the controlled device works a bit more often and that, for the same sea state, it produces more energy. For the St. Pierre site, if the device is controlled $B_{\text {optimal }}$ is equal to $B_{\min }$ but if the device is uncontrolled $B_{\text {optimal }}$ is upper to $B_{\min }$. And so we can see in Figs. 25(a) and 25(c) that the uncontrolled device works more and for frequent and energetic sea states.

By comparing Figs. 25(b) and 25(d) or 26(b) and 26(d), we can see the uncontrolled devices work during a longer period of time

Table 3 Optimal production for the uncontrolled device

\begin{tabular}{|c|c|c|c|c|c|c|c|c|}
\hline & \multicolumn{4}{|c|}{ Optimization/prevailing sea states } & \multicolumn{4}{|c|}{ Optimization/whole scatter diagram } \\
\hline & $\begin{array}{l}T_{0} \\
(\mathrm{~s})\end{array}$ & $\begin{array}{c}B \\
(\mathrm{~N} \mathrm{~s} / \mathrm{m})\end{array}$ & $\begin{array}{l}\text { Energy } \\
\text { (MWh) }\end{array}$ & $\begin{array}{l}\text { Working hours } \\
\text { (h/year) }\end{array}$ & $\begin{array}{l}T_{0} \\
(\mathrm{~s})\end{array}$ & $\begin{array}{c}B \\
(\mathrm{~N} \mathrm{~s} / \mathrm{m})\end{array}$ & $\begin{array}{l}\text { Energy } \\
\text { (MWh) }\end{array}$ & $\begin{array}{l}\text { Working hours } \\
\text { (h/year) }\end{array}$ \\
\hline Yeu (1) & 8 & 100,000 & 138.1 & 4761 & 9 & 350,000 & 562.2 & 8273 \\
\hline Yeu (2) & 8 & 150,000 & 266.4 & 6031 & & & & \\
\hline Point 67 & 10 & 100,000 & 154.6 & 2354 & 9 & 300,000 & 798.6 & 8562 \\
\hline St. Pierre & 9 & 100,000 & 335.5 & 7350 & 10 & 250,000 & 421.0 & 8568 \\
\hline
\end{tabular}

Table 4 Optimal production for the controlled device

\begin{tabular}{|c|c|c|c|c|c|c|c|c|}
\hline & \multicolumn{4}{|c|}{ Optimization/prevailing sea states } & \multicolumn{4}{|c|}{ Optimization/whole scatter diagram } \\
\hline & $\begin{array}{l}T_{0} \\
(\mathrm{~s})\end{array}$ & $\begin{array}{c}B \\
(\mathrm{~N} \mathrm{~s} / \mathrm{m})\end{array}$ & $\begin{array}{l}\text { Energy } \\
(\mathrm{MWh})\end{array}$ & $\begin{array}{l}\text { Working hours } \\
\text { (h/year) }\end{array}$ & $\begin{array}{l}T_{0} \\
(\mathrm{~s})\end{array}$ & $\begin{array}{c}B \\
(\mathrm{~N} \mathrm{~s} / \mathrm{m})\end{array}$ & $\begin{array}{l}\text { Energy } \\
\text { (MWh) }\end{array}$ & $\begin{array}{l}\text { Working hours } \\
\text { (h/year) }\end{array}$ \\
\hline Yeu (1) & 7 & 50,000 & 152.9 & 4761 & 5 & 100,000 & 778.0 & 8336 \\
\hline Yeu (2) & 6 & 50,000 & 263.5 & 6031 & & & & \\
\hline Point 67 & 6 & 40,000 & 314.6 & 2354 & 6 & 100,000 & 1060.0 & 7953 \\
\hline St. Pierre & 6 & 40,000 & 144.1 & 7350 & 7 & 100,000 & 612.7 & 8165 \\
\hline
\end{tabular}



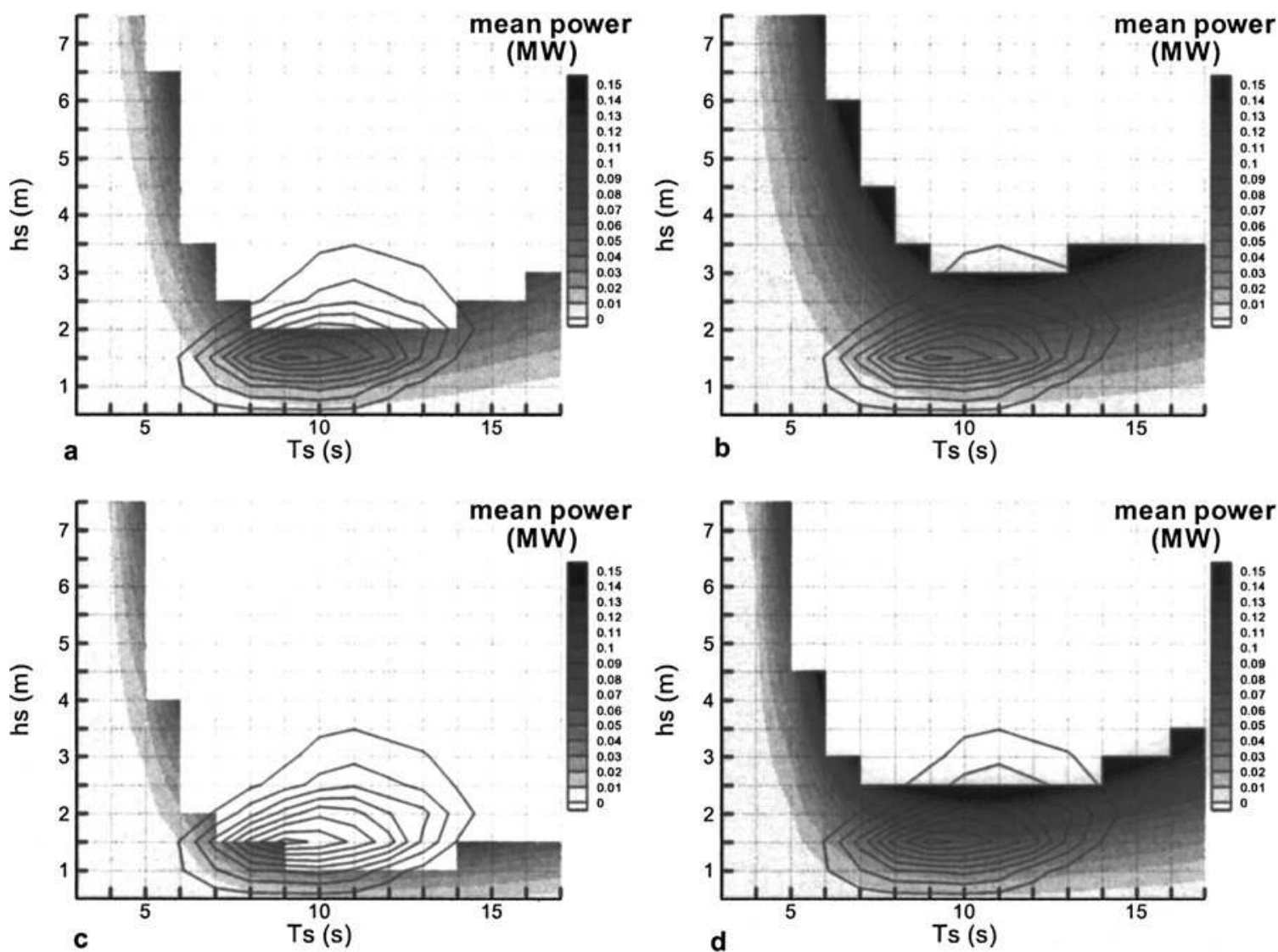

Fig. 25 St. Pierre site: top row $(a, b)$ uncontrolled device; bottom row; $(c, d)$ controlled device; left column $(a, c)$ prevailing sea state optimization; right column $(b, d)$ global optimization
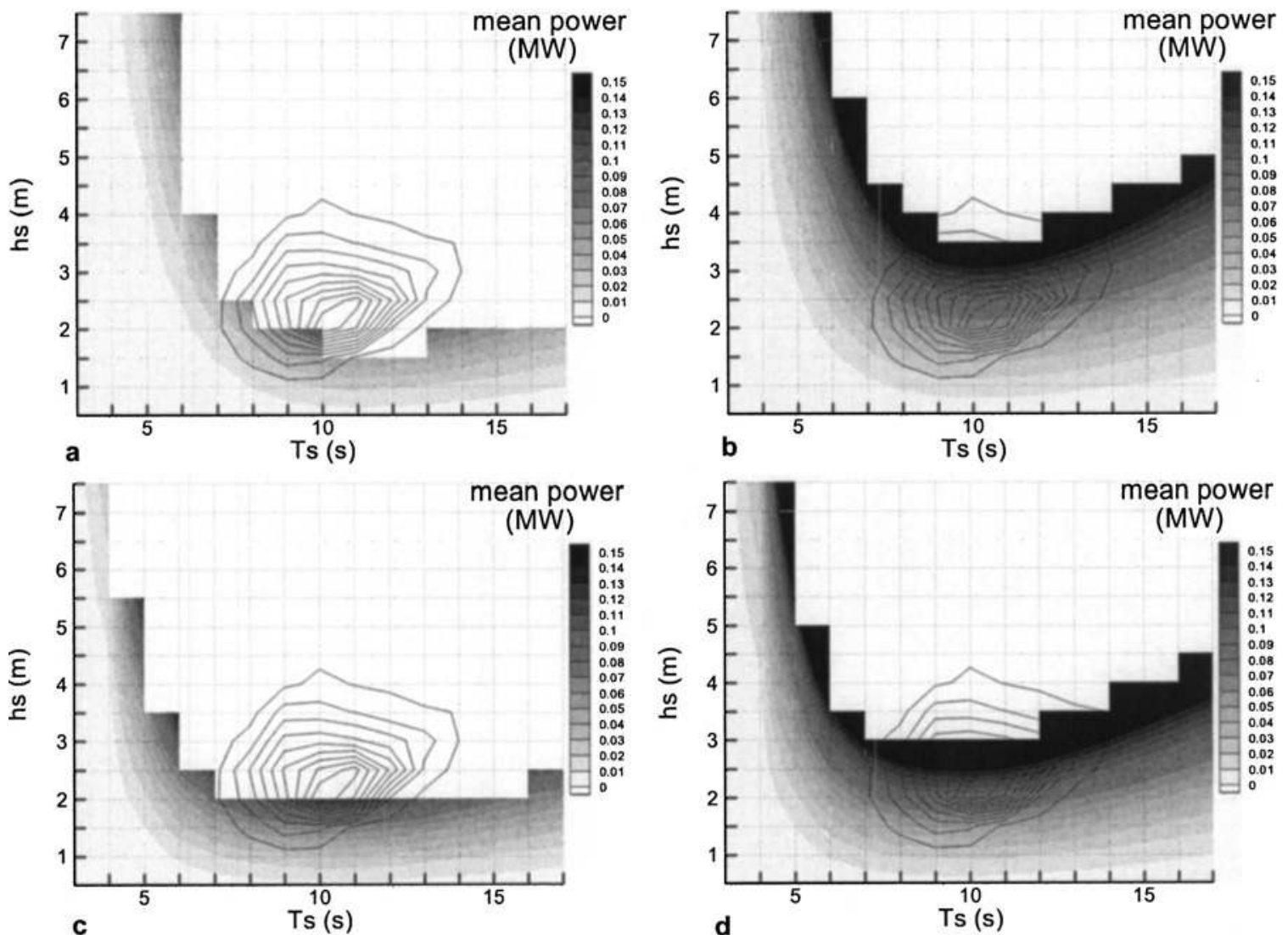

Fig. 26 P67 site: top row $(a, b)$ uncontrolled device; bottom row $(c, d)$ controlled device; left column $(a, c)$ prevailing sea state optimization; right column $(b, d)$ global optimization 
than the controlled devices, but as for a same sea state, the power delivered by the controlled device is larger; finally a controlled device tuned by using all sea state statistics is far more efficient.

\section{Conclusion}

This study has shown that the tuning of a wave energy converter to a given site should necessarily be based on the detailed wave climate, accounting for sea states statistics of the site instead of being tuned for the dominant sea state, as it is often reported. This optimal tuning of the mechanical parameters is even more important than the control. We saw that a badly optimized device, even controlled, can be less efficient than a badly optimized and uncontrolled device. Finally a well optimized device, even uncontrolled, is always more efficient than a badly optimized one, controlled or not. Whatever the site considered, the best device in terms of annual energy production is the one which has been tuned by using detailed sea states statistics, and which works under wave to wave control.

\section{Acknowledgment}

G.D. and A.B. would like to thank the CNRS and the Regional Council of Pays de la Loire for their financial support during this study.

\section{References}

[1] Cummins, W. E., 1962, The Impulse Response Function and Ship Motions, Schiffstechnik, pp. 491-502.
[2] Clément, A. H., 1999, "Using Differential Properties of the Green Function in Seakeeping Computational Codes," in Proceedings of the 7th International Conference Numerical Ship Hydrodynamics, Nantes, pp. 6-5.1,6-5.15.

[3] www.wamit.com

[4] Dehommeau, G., Ferrant, P., Guilbaud, M., 1992, "Calculation and Measurement of Forces on a High Speed Vehicle in Forced Pitch and Heave," Appl. Ocean. Res., 14-2, pp. 119-126.

[5] Duclos, G., Clément, A. H., Chatry, G., 2001, "Absorption of Outgoing Waves in a Numerical Wave Tank Using a Self-Adaptive Boundary Condition," Int. J. Offshore Polar Eng., 11(3), pp. 168-175.

[6] Falnes, J., 2002, "Optimum Control of Oscillation of Wave-Energy Converter," Int. J. Offshore Polar Eng., 12.2, pp. 147-155.

[7] Chatry, G., Clément, A. H., Gouraud, T., 1998, "Self-Adaptive Control of a Piston Wave-Absorber," in Proceedings of the 8th International Offshore and Polar Engineering Conference ISOPE98, Vol. 1, pp. 127-133, Montréal.

[8] Chatry, G., Clément, A. H., Sarmento, A. J. N. A., 2000, "Simulation of a Self-Adaptively Controlled OWC in a Nonlinear Numerical Wave Tank," Int. J. Offshore Polar Eng., 10(4), pp. 269-275.

[9] Korde, U. A., 2002, "Dynamics of a Floating Buoy Under Latching Control," Proceedings of OMAE'02, 21st International Conference on Offshore Mechanics and Artic Engineering, Oslo, June 23-28.

[10] Korde, U. A., 2002, "Latching Control of Deep Water Wave Energy Devices Using an Active Reference," Ocean Eng., 29-11, pp. 1343-1355.

[11] Budal, K., Falnes, J., 1980, Interacting Point Absorbers with Controlled Motion, in Power From Sea Waves, Count, B. M., ed., Academic, NY, pp. 381399.

[12] Greenhow, M., White, S. P., 1997, "Optimal Heave Motion of Some Axisymmetric Wave Energy Devices in Sinusoidal Waves," Appl. Ocean. Res., 19, pp. 141-159.

[13] Babarit, A., Duclos, G., Clement, A. H., 2003, "Benefit of Latching Control for a Heaving Wave Energy Device in a Random Sea," in Proceedings of the 13th International Offshore and Polar Engineering Conference, Vol. 1, pp. 341-348, Honolulu.

[14] Peronno, G., 2003, "Energie des Vagues-Ile de la Réunion," Rapport de stage de fin d'étude, Ecole Generaliste Ingenieur de Marseille. 